\title{
Lithium-0xygen Cells: An Analytical Model to Explain the Key Features in the Discharge Voltage Profiles
}

Ali Rinaldi, ${ }^{1}$ Olivia Wijaya, ${ }^{2,3}$ Harry Hoster ${ }^{1,2,3,{ }^{*}}$

\author{
${ }^{1}$ Technische Universität München, TUM CREATE; \\ ${ }^{2}$ Materials Science and Engineering, Nanyang Technological University, Singapore; \\ ${ }^{3}$ Department of Chemistry, Lancaster University, Lancaster, United Kingdom \\ *h.hoster@lancaster.ac.uk
}

\begin{abstract}
Lithium-oxygen $\left(\mathrm{Li}^{-} \mathrm{O}_{2}\right)$ cells are popular due to their potentially high energy density. A characteristic fingerprint of a given cell is the voltage profile during constant-current discharge. We suggest that the typical initial dip and the following increase of the voltage result from a temporary increase and slow decrease in the concentration of dissolved superoxide, respectively, feeding into the Nernst equation. The steady-state superoxide concentration decreases as the surface area of the solid precipitation product $\left(\mathrm{Li}_{2} \mathrm{O}_{2}\right)$ increases. Importantly, these products bury the electrochemically active carbon surface. Assuming that the electrochemical step only occurs on bare carbon, the Tafel equation provides an expression for the increasing overpotential as a result of the shrinking effective electrode area. This boils the discharge voltage profile down to the sum of two logarithms, grasping all relevant features in recorded discharge voltage profiles.
\end{abstract}

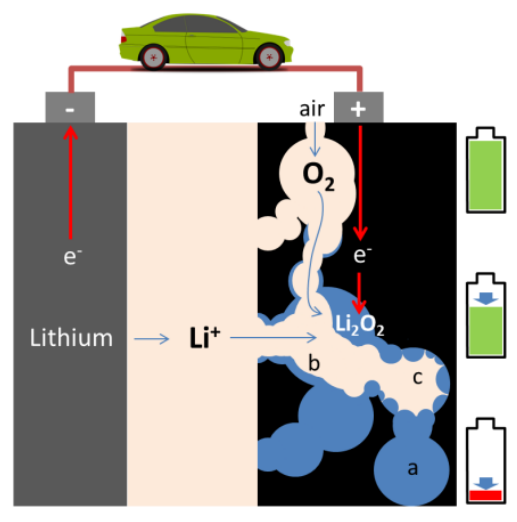

Figure 1. Principle of a Lithium oxygen battery. Ideal scenario: discharge stops when pores are filled with $\mathrm{Li}_{2} \mathrm{O}_{2}(\mathrm{a})$. Real scenario: discharge stops earlier, when $\mathrm{Li}_{2} \mathrm{O}_{2}$ film blocks electron transport $(b, c)$. Two scenarios: $\mathrm{Li}_{2} \mathrm{O}_{2}$ film grows everywhere (b) vs. $\mathrm{Li}_{2} \mathrm{O}_{2}$ particles grow at certain sites but close the gaps at some point (c). 


\section{Introduction}

Their high theoretical gravimetric energy density makes metal-oxygen systems such as lithiumoxygen $\left(\mathrm{Li}^{-} \mathrm{O}_{2}\right)^{[1-5]}$ or sodium-oxygen $\left(\mathrm{Na}-\mathrm{O}_{2}\right)^{[6-11]}$ promising candidates for the next generation of rechargeable batteries for mobile applications. Key challenges on the way to practical implementation are subject of ongoing research. Sluggish kinetics of discharge and charge reactions lead to poor round-trip efficiency and poor rate capability. ${ }^{[12-16]}$ In particular, the high theoretical energy contents, key driver for the research into both systems, are not reached even under ideal laboratory conditions. The overall cell reactions for $\mathrm{Li}^{-} \mathrm{O}_{2}$ is

$2 \mathrm{Li}^{+}+\mathrm{O}_{2}+2 e^{-} \rightarrow \mathrm{Li}_{2} \mathrm{O}_{2}(\mathrm{~s})$

where $(s)$ denotes the solid state of the product.

The theoretical limits are set by the amount of solid, crystalline $\mathrm{Li}_{2} \mathrm{O}_{2}$ that can be accommodated in porous carbon electrodes (see Fig. 1a). In reality, discharge curves at constant current show a suddenly declining discharge voltage, way before all pores are filled (sudden death, see Fig. 2). ${ }^{[15,17-}$ ${ }^{20]}$ There is consensus that the solid product layer inhibits electron transport and thus stops the electrochemical reaction (see Fig. 1). ${ }^{[15,20-26]}$

Many models suggest growth of the respective product as a homogeneous film on the electrode (see Fig. 1b), and the electrochemical reaction to take place on top of that layer. ${ }^{[20-24]}$ However, the electron conductivity of $\mathrm{Li}_{2} \mathrm{O}_{2}{ }^{[15,20,25,26]}$ is so poor that the reaction should break down at even smaller discharge capacities (layers $10 \mathrm{~nm}$ or thinner) than experimentally observed (see, e.g., Fig. 2). There is now some consensus that all experiments which revealed discharge capacities equivalent to an average product thickness on the electrode of $10 \mathrm{~nm}$ or more are actually governed by a socalled solution or solution-precipitation pathway. ${ }^{[24,27-32]}$

A convincing proof of the solution-precipitation mechanism is the observation of donut-shaped $\mathrm{Li}_{2} \mathrm{O}_{2}$ crystallites on glass-fibres (see Fig. 3) that are near the cathode during discharge. Since glass does not conduct electrons, the $\mathrm{Li}_{2} \mathrm{O}_{2}$ must have formed in a chemical reaction, involving an electrochemically formed precursor (EC-mechanism ${ }^{[33]}$ ). 


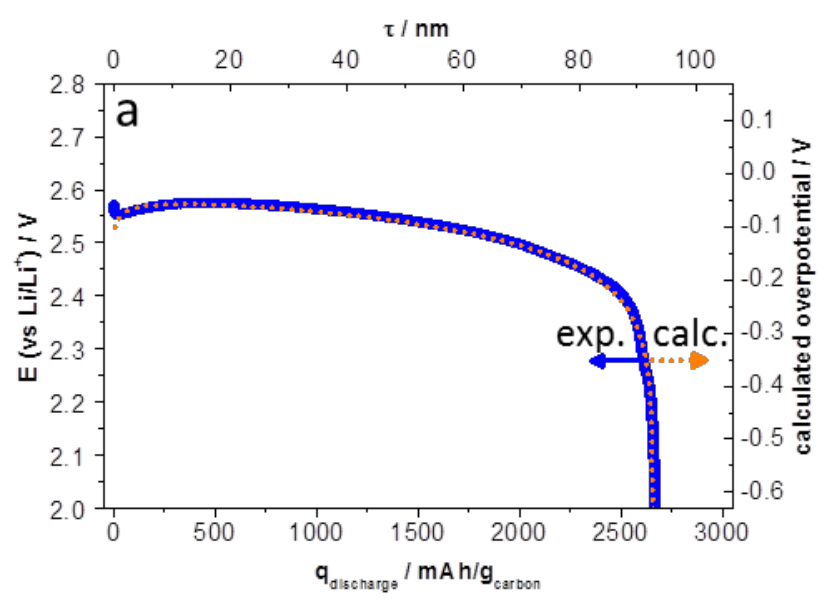

Figure 2. Discharge curve of an $\mathrm{Li}_{-} \mathrm{O}_{2}$ cell: experiment (solid lines) and calculation using equation (5) (dotted lines - see text); graphitized acetylene black in $\mathrm{O}_{2}$ saturated $0.1 \mathrm{M} \mathrm{LiClO}_{4} / \mathrm{DME}$ electrolyte (a); fitted transfer coefficient (see equation 5) $\beta=0.35$.

In this communication, we will show that this EC mechanism leads to a simple mathematical expression for discharge voltage profiles as the ones in Fig. 2. No simulation or numerical integration is required. Data fitting is restricted to one kinetic parameter (effective transfer coefficient) and the maximum discharge capacity, which changes from one system to the next. Considering that the overall reaction involves superoxide as an electroactive intermediate, and that its concentration may vary over the course of the discharge, our model is the first to predict and explain the paradox observation of an increasing cell voltage during the initial phase of the discharge that is frequently observed for $\mathrm{Li}^{-} \mathrm{O}_{2}{ }^{[18,24,34-37]}$ We will eventually discuss how these insights can be utilized to increase the average discharge voltage, thus increasing the energy efficiency of the cell.

Figure 3. $\mathrm{Li}_{2} \mathrm{O}_{2}$ deposits at a glass fibre that was near the cathode during $\mathrm{Li}-$ $\mathrm{O}_{2}$ discharge (graphite cathode discharged to $900 \mathrm{mAh} / \mathrm{g}_{\mathrm{c}}$ at $5 \mathrm{~mA} / \mathrm{g}_{\mathrm{c}}$ in $0.1 \mathrm{M} \mathrm{LiClO}_{4}$ :DME with initial water level of $30 \mathrm{ppm}$ )

\section{Modelling approach and results}

The EC mechanism breaks down into this initial electrochemical step (E-step)

$\mathrm{O}_{2}+e^{-} \rightleftharpoons \mathrm{O}_{2}^{-}$

followed by a chemical step (C-step), here a two-stage precipitation consisting of ${ }^{[24,27-31]}$

$\mathrm{Li}^{+}+\mathrm{O}_{2}^{-} \rightarrow \mathrm{LiO}_{2}^{*}$

(where * reflects that $\mathrm{LiO}_{2}$ are adsorbed on the surface of $\mathrm{Li}_{2} \mathrm{O}_{2}$, respectively) and

$2 \mathrm{LiO}_{2}^{*} \rightarrow \mathrm{Li}_{2} \mathrm{O}_{2}(\mathrm{~s})+\mathrm{O}_{2}$ 
The latter reflect the actual crystal growth step through attachment the disproportionation product $\mathrm{Li}_{2} \mathrm{O}_{2}$ at kink (or half-crystal) sites.

Reaction (2) may involve $\mathrm{LiO}_{2}^{*}$ formation as intermediates in the electrochemical step, and these intermediates may even form a dense layer on the carbon. Such layers would not significantly inhibit reaction (2) because those can also proceed as an outer-Helmholtz-plane reaction. ${ }^{[38]}$ And intermediates are irrelevant for the thermodynamic equilibrium of reaction (2). At much lower potentials (higher overpotentials as required for higher currents), $\mathrm{Li}_{2} \mathrm{O}_{2}$ may also be formed by electrochemical $\mathrm{LiO}_{2}$ reduction, ${ }^{[12,38-40]}$ but this is not the regime to be discussed in this communication.

In the following we will demonstrate how the rates and the interplay of these two steps determine a voltage profile just as it is observed in the experiment. These are the three underlying ideas:

(1) The E-step takes place only on carbon areas. Carbon areas remain exposed until the end of discharge, yet shrinking due to lateral growth of $\mathrm{Li}_{2} \mathrm{O}_{2}$ crystals. If the same electrochemical current I has to be delivered by a smaller area (denoted $A_{\text {active }}$ in the following), the cell voltage will drop, as observed at the end of the discharge curve.

(2) The C- step of superoxide reaction with $\mathrm{Li}^{+}$takes place on the surfaces of the growing $\mathrm{Li}_{2} \mathrm{O}_{2}$ crystals (denoted $A_{\text {deposit }}$ in the following). When the crystals are small, as in the beginning of the discharge, the galvanostatically fabricated $O_{2}^{-}$is consumed by the C-step at smaller rates, thus increasing its concentration $C_{O_{2}^{-}}$as compared to later in the discharge. Through the Nernst equation, this implies a lower equilibrium voltage of reaction (2), as reflected in the lower cell voltage observed in the first quarter of the discharge profile.

(3) The rationale behind (1) and (2) is the low chemical reactivity of basal carbon surfaces. Nakanishi et al. recently calculated that defect and edge sites bind $\mathrm{Li}_{2} \mathrm{O}_{2}$ with an adsorption energy of more than $5 \mathrm{eV}$, which is coarsely ten times stronger than the interaction between $\mathrm{Li}_{2} \mathrm{O}_{2}$ and the basal plane.$^{[41]}$ Hence, any edge sites or defects in a carbon cathode will be natural nucleation points for $\mathrm{Li}_{2} \mathrm{O}_{2}$ crystal growth, but those crystals will have no pronounced tendency to wet the surrounding smooth carbon surface areas.

Demonstrating the accuracy of the approach. The dotted lines in Figs $2 a b$ are reflecting discharge profiles calculated on the base of these three principles. The horizontal axis $\tau$ (see also Figure $4 \mathrm{~d}$ ) measures the amount of $\mathrm{Li}_{2} \mathrm{O}_{2}$ deposit by its virtual thickness if spread out on a planar surface with 
an area equal to that of the carbon cathode, $A_{0}^{\text {carbon }}$. This is more "universal" than the commonly used unit $\mathrm{mAh} / \mathrm{g}_{\text {carbon. }}$. Its relations to current $I_{\text {const }}$ and depth of discharge $\mathrm{q}_{\text {discharge }}$ are

$\frac{d \tau}{d t}=\frac{I_{\text {const }}}{A_{\text {carbon }}^{0}} \frac{V_{\text {deposit }}^{\text {molar }}}{z F} ; \tau=\frac{V_{\text {deposit }}}{A_{\text {carbon }}^{0}}=\frac{q_{\text {discharge }}}{z F} \frac{V_{\text {deposit }}^{\text {molar }}}{A_{\text {carbon }}^{0}} ;$

$\mathrm{z}=2$ for $\mathrm{Li}_{-} \mathrm{O}_{2}(1) . V_{\text {deposit }}^{\text {molar }}=$ molar volume of $\mathrm{Li}_{2} \mathrm{O}_{2}$.

The calculated discharge profiles are based on the following formula:

$$
\begin{aligned}
E(\tau) & =E_{f i x}+\eta_{\text {total }}(\tau)=E_{f i x}+\eta_{c t}(\tau)+\eta_{p c}(\tau) \\
& =E_{f i x}+\frac{R T}{\beta F} \ln \left(1-\left(\frac{\tau}{\tau_{\max }}\right)^{2 / 3}\right)+\frac{R T}{F} \frac{2}{3} \ln \frac{\tau}{\tau_{\max }}
\end{aligned}
$$

$\tau_{\text {max }}$ reflects the maximum discharge capacity;

$E_{f i x}$ : sum of all contributions to the voltage that do not change over the course of the disharge varying overpotentials: $\eta_{c t}$ : charge transfer kinetics; $\eta_{p c}$ : precursor concentration

Deriving the key ideas. Formula (5) is based on the insight that only reaction (2) is directly associated with the cell voltage E. At more negative potentials, the forward (reduction) reaction becomes faster, thus increasing $c_{O_{2}^{-}}$. At steady-state, the concentration of dissolved $\mathrm{O}_{2}\left(c_{O_{2}}\right)$ is maintained constant through the external supply. In the absence of a chemical reaction, the superoxide concentration $c_{O_{2}}$ - will increase until the back-reaction (oxidation) is as fast as the forward reaction. This is the new equilibrium concentration as described by the Nernst equation

$E_{0}=E_{00}^{*}+\frac{R T}{F} \ln \left(\frac{c_{O_{2}}}{c_{O_{2}^{-}}}\right)$.

Overpotential to maintain the rate of the E-step. In the presence of a chemical reaction as in (3), the Nernst equation is still valid, but now $\mathrm{C}_{\mathrm{O}^{-}}$is influenced by reactions (2) and (3). Under constantcurrent (galvanostatic) steady-state conditions, the rates of reactions (2) and (3) will be equal. Reaction (3) sets the pace, given that reaction (2) can reach virtually any rate through polarisation. The interplay of kinetic and concentration overpotentials in reaction (2) can be described through the Butler-Volmer equation ${ }^{[42]}$

$\mathrm{J}=\frac{I_{\text {const }}}{\mathrm{A}_{\text {active }}}=\mathrm{J}_{0}\left[\exp \frac{\alpha \mathrm{F}\left(\mathrm{E}-\mathrm{E}_{0}\right)}{\mathrm{RT}}-\exp \left(-\frac{\beta \mathrm{F}\left(\mathrm{E}-\mathrm{E}_{0}\right)}{\mathrm{RT}}\right)\right](7)$.

$\left(I_{\text {const }}=\right.$ galvanostatic current, $J_{0}=$ exchange current density, $\alpha / \beta=$ transfer coefficients $^{[43]}$ of oxidation/reduction reaction branch of reaction (2), F=Faraday constant, $\mathrm{T}=$ Temperature) 


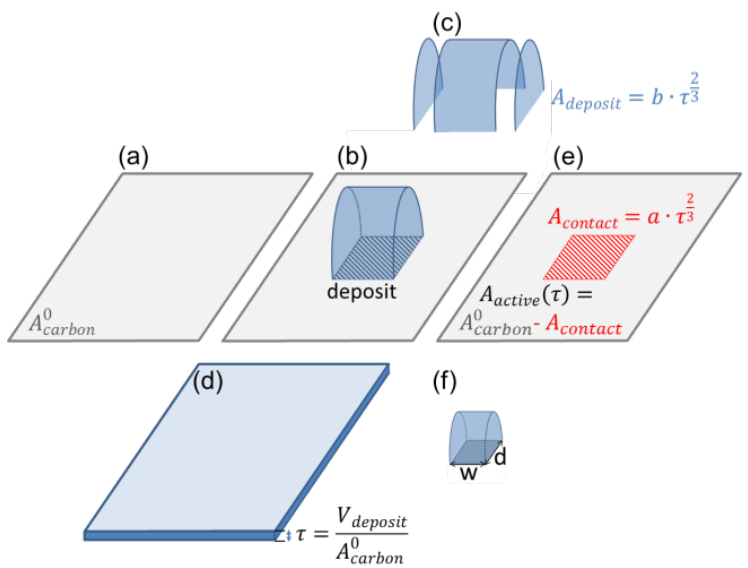

Figure 4. Illustration how the deposited discharge product decreases the surface area available for the electrochemical step (2) and increases the surface area for the chemical step (3). (a) Initial carbon surface area; (b) compact deposit; (c) area of compact deposit = area for reaction (3); (d) effective thickness $\tau$; (e) decreased surface area for reaction (2).

Note that $E_{0}$ from equation (7) is the reference point for the overpotential $\eta_{c t}=\left(E-E_{0}\right)$, so that the increase in $C_{O_{2}^{-}}$is accounted for. Considering only the reduction reaction at sufficiently negative potentials $\left(\left(\mathrm{E}-\mathrm{E}_{0}\right) \ll 0\right)$, one can use the Tafel notation ${ }^{[43]}$

$$
\begin{aligned}
& \ln \left|I_{\text {const }} / A_{\text {active }}\right|=\ln J_{0}-\frac{\beta F}{R T}\left(E-E_{0}\right)=\ln J_{0}-\frac{\beta F}{R T} \eta_{c t} \\
& \Rightarrow \eta_{c t}\left(A_{\text {active }}(\tau)\right)-\eta_{c t}\left(A_{\text {carbon }}^{0}\right)=\frac{\mathrm{RT}}{\beta \mathrm{F}} \ln \left(\frac{A_{\text {active }}(\tau)}{A_{\text {carbon }}^{0}}\right)
\end{aligned}
$$

$A_{\text {active }}(\tau)$ is the fraction of the carbon cathode that is not yet covered by $\mathrm{Li}_{2} \mathrm{O}_{2}$ deposit, i.e., the electrochemically active surface area (ECSA). The interplay of growing deposit and overgrown ECSA is illustrated in Figure 4, at the example of a half-cylinder shaped deposit on a flat carbon substrate. The thickness $\tau$ (Figure $4 \mathrm{~d}$ ) is equal to the deposit volume per electrode surface area. If the deposit crystals continuously grow in all three dimensions, the contact area can be written as $A_{\text {contact }} \cong a$. $\tau^{\frac{2}{3}}$ (Figure 4e). Here, the exponent $2 / 3$ is universal for all kinds of crystal shapes, whereas the contact area coefficient $a$ will depend on shape and orientation of the crystals and on the number of crystals per electrode surface area. For vertical needles/flat discs, $a$ would be small/large. More crystals per surface area will increase a. If we also consider that $A_{\text {active }}(\tau)=0$ for $\tau=\tau_{\text {max }}$, we get

$$
\begin{aligned}
& A_{\text {active }}(\tau)=A_{\text {carbon }}^{0}-A_{\text {contact }} \cong A_{\text {carbon }}^{0}-a \cdot \tau^{\frac{2}{3}}=A_{\text {carbon }}^{0}\left(1-\left(\frac{\tau}{\tau_{\text {max }}}\right)^{2 / 3}\right) \\
& \Rightarrow \eta_{c t}\left(A_{\text {active }}(\tau)\right)-\eta_{c t}\left(A_{\text {carbon }}^{0}\right)=\frac{\mathrm{RT}}{\beta \mathrm{F}} \ln \left(1-\left(\frac{\tau}{\tau_{\max }}\right)^{2 / 3}\right)
\end{aligned}
$$


This is the $\eta_{c t}$ term in equation 5 , which shapes the declining part of the discharge curve, including the steep "sudden death" in the end. $\eta_{c t}\left(A_{\text {carbon }}^{0}\right)$ does not change with $\tau$ and is included in $E_{f i x}$ in equation (5).

How the superoxide concentration creates the voltage peak. The precursor related overpotential $\eta_{p c}$ relates to the C-step of the reaction, which is only indirectly influenced by the electrode potential. Yet, it is responsible for the seemingly paradox voltage increase in the initial phase of discharge. The reason is the constant discharge current that creates $\mathrm{O}_{2}^{-}$at a fixed rate. Initially the electrolyte slowly enriches in superoxide, which causes the potential to become less positive (steep voltage decline at the beginning of the discharge profiles in Figure 2). Once the $\mathrm{O}_{2}^{-}$concentration $\mathrm{C}_{\mathrm{O}_{2}^{-}}$ is sufficiently high, the C-step becomes thermodynamically and kinetically favourable. In the initial absence of $\mathrm{Li}_{2} \mathrm{O}_{2}$ nuclei, the $\mathrm{C}$-step will take place via heterogeneous nucleation at other chemically reactive sites of the electrode (e.g., carbon edge or defect sites ${ }^{[41]}$ ). The created $\mathrm{Li}_{2} \mathrm{O}_{2}$ nuclei grow in volume and surface area $A_{\text {deposit }}$. Once $A_{\text {deposit }}$ is sufficiently large, the $C$-step will reach the rate of the E-step, stopping the increase of $C_{O_{2}^{-}}$(local minimum at the beginning of the discharge profiles in Figure 2). From that point, steady-state conditions, where E- and C-step occur at equal rates, can be maintained. For galvanostatic discharge, both are determined by the fixed current, which yields for the C-step

const. $=\frac{d \tau}{d t}=k_{c} \cdot A_{\text {deposit }}(\tau) \cdot c_{O_{2}^{-}}(\tau)$

$\Leftrightarrow c_{O_{2}^{-}}(\tau)=\frac{d \tau}{d t} \frac{1}{k_{c}} A_{\text {deposit }}(\tau)^{-1} \quad$ (12), $k_{c}=$ rate constant.

Here we assume that the growth rate of the deposit depends on how often a dissolved $O_{2}^{-}$reaches the surface of an existing $\mathrm{Li}_{2} \mathrm{O}_{2}$ surface $\left(A_{\text {deposit }}\right)$. This rate, in turn, is proportional to the product of deposit surface area $\mathrm{A}_{\text {deposit }}$ and $c_{O_{2}^{-}}$. This implies an assumption of first-order kinetics for the disproportionation reaction of the C-step, which for the growth of $\mathrm{Li}_{2} \mathrm{O}_{2}$ was confirmed in experiments. ${ }^{[4]]}$ Although equation 4 a may intuitively suggest second order kinetics, the first-order behaviour can be rationalized by an abundance $\mathrm{LiO}_{2}$ on the surfaces of the growing $\mathrm{Li}_{2} \mathrm{O}_{2} \cdot{ }^{[32]}$

Based on equation (12), $\mathrm{A}_{\text {deposit }}$ and $c_{O_{2}^{-}}$increase and decrease over the course of the discharge, respectively. Through the Nernst equation (6) and using the end of discharge $\tau_{\max }$ as a convenient reference point, we get the contribution of the growing deposit surface to the cell voltage:

$E_{0}(\tau)=E_{0}\left(\tau_{\max }\right)+\frac{R T}{F} \ln \left(\frac{A_{\text {deposit }}(\tau)}{A_{\text {deposit }}\left(\tau_{\max }\right)}\right)$ 
In analogy to the treatment of the deposit/carbon contact area, we can calculate the exposed deposit surface area (see also Figure 4c) through

$$
A_{\text {deposit }}(\tau) \cong b \cdot \tau^{\frac{2}{3}}
$$

This yields

$$
\begin{aligned}
& E_{0}(\tau)=E_{0}\left(\tau_{\max }\right)+\frac{R T}{F} \ln \left(\frac{\tau}{\tau_{\max }}\right)^{\frac{2}{3}} \\
& \Leftrightarrow \eta_{p c}(\tau)=E_{0}(\tau)-E_{0}\left(\tau_{\max }\right)=\frac{R T}{F} \frac{2}{3} \ln \frac{\tau}{\tau_{\max }}(16) .
\end{aligned}
$$

This completes the explanation of equation (5). Despite many simplifying assumptions the equation, reproduces the key features of experimental discharge voltage profiles with surprising accuracy (see Figure 2). In the following, we will discuss the microscopic phenomena behind the simulated and measured voltage profile in some more detail, making use of a simple, yet sufficiently accurate toy model.

\section{Discussion}

The toy model and the resulting contributions to the discharge profile are shown in detail in Figure 5. The dashed and the dotted line in Figure $5 a$ reflect the surface areas that are relevant for the electrochemical and the chemical step, respectively, i.e., the yet uncovered carbon (equation 10) and the surface of the solid $\mathrm{Li}_{2} \mathrm{O}_{2}$ deposit (equation 15). Figure $5 \mathrm{~b}$ illustrates the changes in those surface areas and the resulting changes in the dissolved superoxide species in a geometrically simplified way. The flat lying slab represents the carbon electrode, with the black rectangles marking the initial nucleation points. For simplicity, we assume that those points form a rectangular lattice, and that the solid deposit grows in the shape of half-cylinders (Figure 4) on top of them. The aspect ratio of the growing cylinders is equal to that of the lattice formed by the defects. Hence, all gaps between the deposited particles close simultaneously towards the end, causing the "sudden death" of the discharge. 


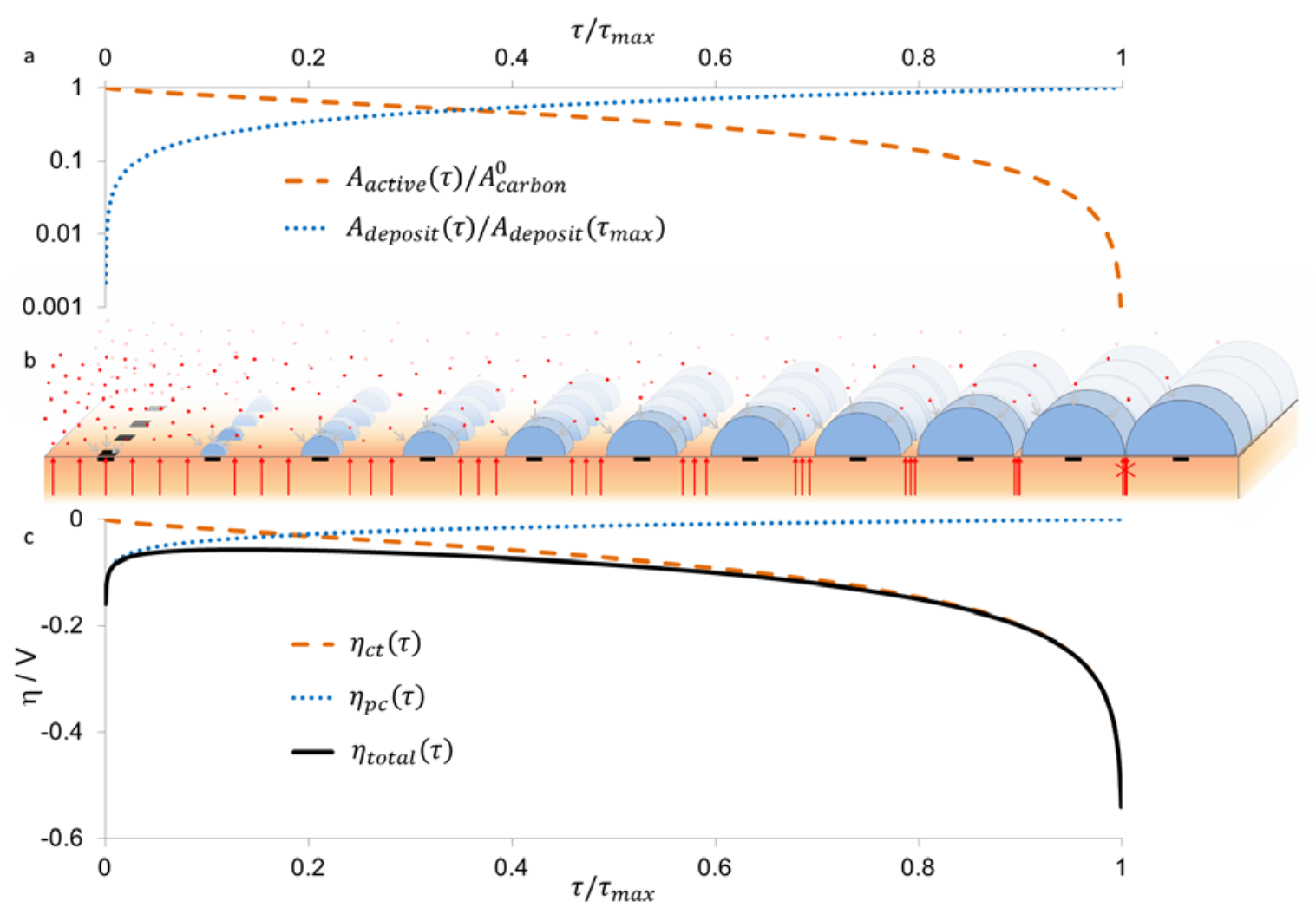

Figure 5. Illustration of a simulated discharge profile based on the EC mechanism. (a) normalized surface areas active for $E$ (dashed line, equation 15 ) and $C$ (dotted line, equation 10 ) step; (b) toy model of the interface structure: flat lying slab = carbon surface; dots $=\mathrm{O}_{2}^{-}$ions; black squares = defect sites where C-step initiates; blue half-cylinders = crystallites initially growing on top of the defect sites and eventually merging, thus blocking the E-step; arrows = local electron current density; (c) charge-transfer and precursor determined overpotentials according to equations 11 and 16 , respectively, and overall overpotential according to equation $5(\beta=0.35$, see Figure $2 a)$.

Note that had we allowed particles with different shapes or less regular distribution, we would have to explicitly consider the merging of some particles before the entire surface closes, requiring a more sophisticated mathematical treatment. That would not, however, significantly affect the shapes of the resulting voltage profiles, since the logarithms in equations 11 and 16 make them sensitive only to the orders of magnitude.

The $O_{2}^{-}$concentration is reflected by the density of the small dots in Figure $5 \mathrm{~b}$. With the C-step initially only taking place at the nucleation sites, very little $\mathrm{O}_{2}^{-}$is consumed, leading to a high initial concentration. As the surface area of the deposit grows, the $\mathrm{C}$ step increases in rate and the $\mathrm{O}_{2}^{-}$ concentration decreases (eq. 12). The growth of the deposit also implies growth of its interface with the carbon electrode, thus decreasing the electrochemically active surface area. The galvanostatic conditions demand that the local current density in the remaining exposed areas increases, as indicated by the lateral distance of the vertical arrows. At the end of discharge, it would have to 
reach infinity, which would require an infinitely high overpotential, equivalent to "sudden death". Equations 9 and 14 transform the surface areas for the $\mathrm{E}$ - and the $\mathrm{C}$-step into the respective overpotentials, as they are plotted in Figure $5 \mathrm{c}$.

The deposit layers are effectively inert for the E-step. One central simplification in our model is to neglect the possibility of electrochemical reactions on top of a thin $\mathrm{Li}_{2} \mathrm{O}_{2}$ layer. That scenario was thoroughly discussed in many previous works, ${ }^{[20-24]}$ but given the rapid decrease of electron conductivity with layer thickness, ${ }^{[20]}$ the rate of the E-step on such a layer would always be orders of magnitude lower than on the exposed carbon area, making it as irrelevant as the current through a large resistor in parallel to a small one.

Hard-wired components of the voltage profile. The exact details of the growth morphology do not really matter for these curves, as obvious from the connections between equations 9 and 11 and 14 and 16, respectively. The curve shape is determined by the two opposing logarithm curves, the factor $2 / 3$, which reflects the connection between deposit volume and surface area / contact area, and by the charge transfer coefficient $\beta$. For a given temperature and current, $\beta$ determines how much the overvoltage needs to increase when the ECSA shrinks by an order of magnitude. The value of $\beta=0.35$ (see Figures 2 and $6 c$ ) is equivalent to $170 \mathrm{mV} /$ decade. Higher/lower values of $\beta$ would lead to a lower/higher slope of the ECSA dominated overpotential (dashed line in Figure $5 \mathrm{c}$ ), thus shifting the potential peak of the discharge curve to the right/left. For a single-electron reaction across a symmetric energy barrier, one would expect $\beta=0.5 .^{[43]} \beta$, as the kinetic parameter governing $\mathrm{O}_{2}^{-}$formation, can in principle be determined independently, i.e., through fast cyclic voltammetry or other methods that yield Tafel slopes. ${ }^{[40,43,45]}$ For the electrodes and electrolytes used here, however, such measurements are yet to be performed. This means that at this point we cannot disentangle the influences of electrochemical kinetics and the rate at which the ECSA is overgrown by the deposit.

Limits of applicability. When it comes to the declining part of the voltage profile, our analytic expression yields the same results as the nucleation and growth simulations recently published by Lau and Archer. ${ }^{[45]}$ They assumed nucleation of $\mathrm{Li}_{2} \mathrm{O}_{2}$ on randomly distributed defect sites and growth of hemispheric particles whose lateral growth increasingly blocks the ECSA above which they grow. As in our toy model, their simplified growth morphology effectively yields a voltage profile dominated by the decreasing ECSA as described by equations 10 and 11 . Where we assume that nucleation exclusively occurs at chemically active defect sites and only at the beginning of the discharge, however, their model takes into account the possibility of ongoing nucleation during the discharge process. This will lead to a faster decline of the cell voltage than our model would antici- 
pate. In their picture, this decline would even be self-accelerating, since the increasing overpotential (due to decreasing ECSA) would further increase the formation rate of new $\mathrm{Li}_{2} \mathrm{O}_{2}$ nuclei because that process takes place in the inner Helmholtz-layer where the potential directly influences all processes. ${ }^{[45]}$ Ongoing nucleation would explain why our analytic expression yields a best fit with experimental data by assuming slightly higher than expected Tafel slopes (i.e., $\beta<0.5$ ). In our picture of a strict EC-mechanism, however, the effect of the overpotential on nucleation would only be an indirect one, because the C-step does not involve charge transfer. Hence, the more negative potential itself would not directly lead to more nucleation. Any nucleation sites not filled at the beginning of the discharge process would necessarily be chemically less reactive. Nucleation at such sites would only become favourable at even higher $\mathrm{O}_{2}^{-}$concentrations, but since the latter decrease during the discharge, such conditions would not be reached in our picture. However, at sufficiently high overpotentials, further reduction of $\mathrm{LiO}_{2}$ towards $\mathrm{Li}_{2} \mathrm{O}_{2}$ may also be occur electrochemically, ${ }^{[12,38-40]}$ so that the self-accelerating effect of the voltage decline should occur at some point during the discharge.

The initial voltage dip. By focusing only on the steady-state conditions of the galvanostatic discharge, the formula for the discharge curve (equation 5) does not include the local voltage dip at the very beginning of the discharge. As discussed above, the initial steep decline of the cell voltage reflects the increase of the $\mathrm{O}_{2}^{-}$concentrations due to the ongoing E-step at negligible rates of the Cstep. The latter only sets in once the formation of $\mathrm{Li}_{2} \mathrm{O}_{2}$ crystals becomes thermodynamically favourable. Apart from nucleation effects, this requires the chemical potential of the dissolved $\mathrm{O}_{2}^{-}$ species to become sufficiently high, which in turn requires their concentration to be high. The local minimum of the cell voltage reflects the point where the C-step not only becomes thermodynamically favourable, but also occurs with the same (kinetic) rate as the $O_{2}^{-}$formation through the Estep, which requires an even higher concentration to be reached. That concentration will depend on the type and density of nucleation sites. The point in time where that concentration is reached, however, will not only depend on the electrode and electrolyte materials, but also on the respective experimental setup and details such as the porosity of the electrode: for the same current, a smaller volume of electrolyte will reach the minimum $\mathrm{O}_{2}^{-}$concentration sooner than a larger one. If the electrode thickness exceeds a few $\mu \mathrm{m}$, even the transport diffusion of $\mathrm{O}_{2}^{-}$may have an influence on the voltage transient. Hence, before steady-state conditions are reached, the shape of the discharge profile may differ from the one predicted by equation 5 , and it may vary from one setup to the next.

Catalytic effect of defects. Electrodes with higher defect density require smaller $\mathrm{O}_{2}^{-}$concentrations for the same (initial) discharge rates, in perfect agreement with the experimental observation that 
electrodes with higher densities of surface defects exhibit higher initial discharge voltages. ${ }^{[37,41,46,47]}$ Defects whose higher chemical reactivity makes them nucleation points for the solid discharge product may also stabilize adsorbed $\mathrm{O}_{2}$, thus potentially acting as electrocatalysts for the initial Estep. ${ }^{[37,48]}$ This "double function" would naturally limit any electrocatalytic effect to the very beginning of the discharge curve. What will persist is the effect of the initially higher nucleation density, which increases the surface-to-volume-ratio of the solid deposit, thus maintaining lower steadystate $\mathrm{O}_{2}^{-}$concentrations throughout the discharge. According to equations (14) and (5), this should shift the entire voltage profile to higher values, in good agreement with the observation that electrodes with higher defect densities tend to maintain higher cell voltages throughout the entire discharge process. ${ }^{[37,41,46,47]}$ In experiments where electrodes with high defect densities are operated at relatively low currents, the influence of the $\mathrm{O}_{2}^{-}$concentration may even become negligible: if any produced $\mathrm{O}_{2}^{-}$is consumed by precipitation at a nearby nucleus, its concentration may stay low right from the beginning, i.e., the Nernstian potential regime will not be reached. In that case, the voltage profile will lack the initial increase and be dominated by the contribution from equation 11 (dashed line in Figure 5c).

In summary, we have demonstrated that the voltage profiles for constant-current discharge $\mathrm{Li}^{-\mathrm{O}_{2}}$ cells can be modelled with a simple analytic expression, specifically, the weighted sum of two logarithmic curves with opposite abscissae. The logarithms result from the Nernst and the Tafel (or Butler-Volmer) equations, which are applied in a textbook manner to describe the overpotentials resulting from the concentration and production rate of dissolved $O_{2}^{-}$as a key species, respectively. For the first time, this appropriately considers the possibility and the effects of varying $\mathrm{O}_{2}^{-}$ concentrations over the course of the discharge. Growing $\mathrm{Li}_{2} \mathrm{O}_{2}$ particles lower the $\mathrm{O}_{2}^{-}$concentration, but also increasingly block the electrochemically active surface area, so that the same current has to be delivered by a shrinking electrode area. Our simple approach provides a quick understanding of the key elements of experimentally observed discharge curves. Its shape is largely "hardwired" through the two logarithmic functions and does not require extensive parameter fitting. The most important selling point $\mathrm{Li}_{-} \mathrm{O}_{2}$ cells is their potentially high energy density. Our approach underlines that the blocking of the electrochemically active area, which eventually terminates the discharge, could be delayed by minimizing the growth on top of the conducting surface. For deposits growing on the electrode, a needle-shape would yield the highest discharge capacity. Making systematic use of the solution pathway, an ideal electrode for technical applications could be a blend: a rather smooth, defect free but conducting material for the E-step, and a defect-rich nucleation surface to predominantly accept the product via the C-step. As recently demonstrated, ${ }^{[46]}$ the latter component may even be electrically insulating. 


\section{References}

[1] K. Abraham, Z. Jiang, J. Electrochem. Soc. 1996, 143, 1-5.

[2] T. Ogasawara, A. Débart, M. Holzapfel, P. Novák, P. G. Bruce, J. Am. Chem. Soc. 2006, 128, 1390-3.

[3] G. Girishkumar, B. McCloskey, A. C. Luntz, S. Swanson, W. Wilcke, J. Phys. Chem. Lett. 2010, 1, 2193-2203.

[4] J.-S. Lee, S. Tai Kim, R. Cao, N.-S. Choi, M. Liu, K. T. Lee, J. Cho, Adv. Energy Mater. 2011, 1, 34-50.

[5] J. Christensen, P. Albertus, R. S. Sanchez-Carrera, T. Lohmann, B. Kozinsky, R. Liedtke, J. Ahmed, A. Kojic, J. Electrochem. Soc. 2012, 159, R1.

[6] S. K. Das, S. Lau, L. a. Archer, J. Mater. Chem. A 2014, 2, 12623.

[7] P. Hartmann, M. Heinemann, C. L. Bender, K. Graf, R. P. Baumann, P. Adelhelm, C. Heiliger, J. Janek, J. Phys. Chem. C 2015, 119, 22778-22786.

[8] Z. Jian, Y. Chen, F. Li, T. Zhang, C. Liu, H. Zhou, J. Power Sources 2014, 251, 466-469.

[9] B. D. McCloskey, J. M. Garcia, A. C. Luntz, J. Phys. Chem. Lett. 2014, 5, 1230-1235.

[10] P. Hartmann, C. L. Bender, J. Sann, A. K. Durr, M. Jansen, J. Janek, P. Adelhelm, Phys. Chem. Chem. Phys. 2013, 15, 11661-11672.

[11] P. Hartmann, C. L. Bender, M. Vračar, A. K. Dürr, A. Garsuch, J. Janek, P. Adelhelm, Nat. Mater. 2013, 12, 228-32.

[12] Z. Peng, S. A. Freunberger, L. J. Hardwick, Y. Chen, V. Giordani, F. Bardé, P. Novák, D. Graham, J.-M. Tarascon, P. G. Bruce, Angew. Chem. Int. Ed. Engl. 2011, 50, 6351-5.

[13] P. G. Bruce, S. A. Freunberger, L. J. Hardwick, J.-M. Tarascon, Nat. Mater. 2012, 11, 19-29.

[14] Y.-C. Lu, B. M. Gallant, D. G. Kwabi, J. R. Harding, R. R. Mitchell, M. S. Whittingham, Y. ShaoHorn, Energy Environ. Sci. 2013, 6, 750.

[15] B. D. McCloskey, C. M. Burke, J. E. Nichols, S. E. Renfrew, Chem. Commun. 2015, 51, 1270112715.

[16] Z. Ma, X. Yuan, L. Li, Z.-F. Ma, D. P. Wilkinson, L. Zhang, J. Zhang, Energy Environ. Sci. 2015, 8, 2144-2198.

[17] J. Højberg, B. D. McCloskey, J. Hjelm, T. Vegge, K. Johansen, P. Norby, A. C. Luntz, ACS Appl. Mater. Interfaces 2015, 7, 4039-4047.

[18] A. Rinaldi, O. Wijaya, H. E. Hoster, D. Y. W. Yu, ChemSusChem 2014, 7, 1283-1288.

[19] C. Xia, M. Waletzko, L. Chen, K. Peppler, P. J. Klar, J. Janek, ACS Appl. Mater. Interfaces 2014, 6, 12083-92.

[20] V. Viswanathan, K. S. Thygesen, J. S. Hummelshøj, J. K. Nørskov, G. Girishkumar, B. D. McCloskey, A. C. Luntz, J. Chem. Phys. 2011, 135, 214704.

[21] J. B. Varley, V. Viswanathan, J. K. Nørskov, A. C. Luntz, Energy Environ. Sci. 2014, 7, 720.

[22] a. C. Luntz, V. Viswanathan, J. Voss, J. B. Varley, J. K. Nørskov, R. Scheffler, a. Speidel, J. Phys. Chem. Lett. 2013, 4, 3494-3499.

[23] S. A. Freunberger, Y. Chen, N. E. Drewett, L. J. Hardwick, F. Bardé, P. G. Bruce, Angew. Chemie Int. Ed. 2011, 50, 8609-8613.

[24] N. B. Aetukuri, B. D. McCloskey, J. M. García, L. E. Krupp, V. Viswanathan, A. C. Luntz, Nat. Chem. 2015, 7, 50-56. 
[25] M. Safari, B. D. Adams, L. F. Nazar, 2014.

[26] O. Gerbig, R. Merkle, J. Maier, Adv. Mater. 2013, 25, 3129-33.

[27] M. J. Trahan, I. Gunasekara, S. Mukerjee, E. J. Plichta, M. a. Hendrickson, K. M. Abraham, J. Electrochem. Soc. 2014, 161, A1706-A1715.

[28] L. Johnson, C. Li, Z. Liu, Y. Chen, S. a. Freunberger, J.-M. Tarascon, P. C. Ashok, B. B. Praveen, K. Dholakia, P. G. Bruce, Nat. Chem. 2014, 6, 1091-1099.

[29] K. M. Abraham, J. Electrochem. Soc. 2015, 162, A3021-A3031.

[30] A. Khetan, A. Luntz, V. Viswanathan, J. Phys. Chem. Lett. 2015, 6, 1254-1259.

[31] T. Liu, M. Leskes, W. Yu, A. J. Moore, L. Zhou, P. M. Bayley, G. Kim, C. P. Grey, Science (80-. ). 2015, 350, 530-533.

[32] D. Zhai, H. Wang, K. C. Lau, J. Gao, P. C. Redfern, F. Kang, B. Li, E. Indacochea, U. Das, H. Sun, et al., 2014.

[33] A. J. Bard, L. R. Faulkner, Electrochemical Methods - Fundamentals and Applications, John Wiley \& Sons, New York, 2001.

[34] C. Y. Jung, T. S. Zhao, L. An, J. Power Sources 2015, 273, 440-447.

[35] K.-H. Xue, E. McTurk, L. Johnson, P. G. Bruce, A. A. Franco, J. Electrochem. Soc. 2015, 162, A614-A621.

[36] B. Horstmann, B. Gallant, R. Mitchell, W. G. Bessler, Y. Shao-Horn, M. Z. Bazant, J. Phys. Chem. Lett. 2013, 4, 4217-4222.

[37] S. Nakanishi, F. Mizuno, T. Abe, H. Iba, Electrochemistry 2012, 10, 783-786.

[38] K. M. Abraham, J. Electrochem. Soc. 2014, 162, A3021-A3031.

[39] C. O. Laoire, S. Mukerjee, K. M. Abraham, E. J. Plichta, M. a. Hendrickson, J. Phys. Chem. C 2009, 113, 20127-20134.

[40] C. O. Laoire, S. Mukerjee, K. M. Abraham, E. J. Plichta, M. A. Hendrickson, J. Phys. Chem. C 2010, 114, 9178-9186.

[41] S. Nakanishi, F. Mizuno, K. Nobuhara, T. Abe, H. Iba, Carbon N. Y. 2012, 50, 4794-4803.

[42] W. Schmickler, E. Santos, Interfacial Electrochemistry, 2010.

[43] R. Guidelli, R. G. Compton, J. M. Feliu, E. Gileadi, J. Lipkowski, W. Schmickler, S. Trasatti, Pure Appl. Chem. 2014, 86, 259-262.

[44] Z. Peng, S. A. Freunberger, L. J. Hardwick, Y. Chen, V. Giordani, F. Bardé, P. Novák, D. Graham, J.-M. Tarascon, P. G. Bruce, Angew. Chemie Int. Ed. 2011, 50, 6351-6355.

[45] S. Lau, L. A. Archer, Nano Lett. 2015, 15, 5995-6002.

[46] C. Xia, M. Waletzko, K. Peppler, J. Janek, J. Phys. Chem. C 2013, 117, 19897-19904.

[47] E. Yilmaz, C. Yogi, K. Yamanaka, T. Ohta, H. R. Byon, Nano Lett. 2013, 13, 4679-84.

[48] B. D. Adams, C. Radtke, R. Black, M. L. Trudeau, K. Zaghib, L. F. Nazar, Energy Environ. Sci. 2013, 6, 1772. 